\author{
Alfes, K., Shantz, A.D., Bailey, C., Conway, E., Monks, K., \& Fu, N. (2019). \\ Perceived human resource system strength and employee reactions toward change: \\ Revisiting human resource's remit as change agent. Human Resource Management, 58(3),
}

239-252.

\title{
Perceived HR system strength and employee reactions toward change: Revisiting HR's remit as change agent
}

\begin{abstract}
Although scholars have highlighted HR's important role as change agent, we know little about the extent to which HR influences the change context to foster positive employee responses and support organizational changes. This study positions perceived HR system strength as an important internal context factor which influences employees' reactions toward change. Drawing on emotion theory and social exchange theory, we analyze the mechanisms through which employees' perceptions of HR system strength lead to positive employee responses to organizational change. Data from 704 employees in a UK police force showed that employees' perceptions of HR system strength were positively related to their ability to cope with organizational change and that this relationship was simultaneously mediated by state positive affect and perceived organizational support. Moreover, our findings revealed that coping with organizational change was positively related to employees' change-supportive behavior. This study is important because it broadens the remit of HR's role as change agent and provides valuable insight into how HR positively influences employee outcomes during organizational change.
\end{abstract}


Keywords: change agent role; HR system strength; state positive affect; perceived organizational support; coping with organizational change; change-supportive behavior, police force 


\section{Introduction}

Over 20 years ago, human resource (HR) professionals were challenged with a new mandate to become change agents (Storey, 1992; Ulrich, 1997). Since then, research has focused on different ways through which HR assumes this role to facilitate successful organizational change and contribute to sustained organizational performance (Alfes, Truss, \& Gill, 2010; Long, Wan Ismail, \& Amin, 2013). Specifically, studies have suggested that HR plays an important role in managing the content and the implementation of change (Alfes et al., 2010). Whereas the former involves changes in HR practices to foster positive employee reactions to the change, the latter relates to HR activities aimed at generating employee support throughout the various stages of the change.

Although this body of research has brought us a long way in understanding how HR can contribute toward organizational change, one aspect that has largely been ignored is HR's role in managing the change context, i.e. the internal or external circumstances that influence change effectiveness (Herold, Fedor, \& Caldwell, 2007; Rafferty \& Restubog, 2017; Self, Armenakis, \& Schraeder, 2007). The lack of understanding of the change context is an important omission as recent studies suggest that, aside from change content and change implementation, the change context is a key factor influencing employee reactions toward change, and therefore a crucial determinant that influences whether change programs can be completed successfully (Choi, 2011; Rafferty \& Restubog, 2017). Hence, understanding ways through which HR provides a context to orchestrate change is therefore of relevance for HR scholars and practitioners.

Guided by Bowen and Ostroff's (2004) HR system strength theory, we integrate research on strong HR systems and organizational change by examining the extent to which employee perceptions of the strength of the HR system, as one indicator of the change context, are related to coping with change, and further to change-supportive behavior. In addition, we examine two 
mediating mechanisms through which perceptions of a strong HR system lead employees to cope with change and demonstrate change-supportive behavior. Taking into account that employee reactions to organizational phenomena derive from the "heart" and the "mind" (Kark Smollan, 2006), we draw from the theory of emotions (Lazarus, 1991; Lazarus \& Folkman, 1984) and social exchange theory (Blau, 1964) to examine an affective [i.e., state positive affect (Watson, 2000)] and a cognitive [i.e., perceived organizational support (Eisenberger, Huntington, Hutchison, \& Sowa, 1986)] mediator of the HR system strength-coping relationship. Specifically, we test the proposition that employees are better equipped to cope with change because a strong HR system elicits positive feelings about the change, and because it signals to them that the organization supports them and cares about their wellbeing.

With this paper, we make three distinct contributions to the human resource management and organizational change literatures. First, we contribute to the change management literature by exploring how perceived HR system strength - one aspect of the internal change context influences employee change outcomes. Although the change context encompasses a number of external (i.e. industry characteristics; advances in technology) and internal (i.e. strategic direction; work requirements) factors (Armenakis \& Bedeian, 1999; Walker, Armenakis, \& Bernerth, 2007), we focus on HR's role, because of its potential to influence change outcomes, which has not yet been examined in the extant literature. Specifically, we suggest that HR system strength is an important factor of the internal change context because it creates a common frame of reference that helps employees to interpret and support the change.

Second, we contribute to literature which speaks to the role of HR as a change agent, in that we provide a starting point for a new area of research that links HR system strength to successful change. Our approach is guided by the body of work that focuses on perceptions of HR system 
strength. Although Bowen and Ostroff's (2004) HR system strength theory was originally conceptualized at the organizational level, our study is aligned with the vast majority of empirical evidence and theory building that has taken an individual-level perspective by examining employees' perceptions of HR system strength (e.g., Katou, Budhwar, \& Patel, 2014; Li, Frenkel, \& Sanders, 2011; Sanders, Dorenbosch, \& De Reuver, 2008).

By adding to these studies we make our third contribution in that we test whether a strong HR system influences yet another category of individual-level outcomes, i.e. employees' ability to cope with change and further change-supportive behavior. Although HR system strength theory has gained traction in HR scholarship (see Hewett, Shantz, Mundy, \& Alfes, 2017 for a review), no study that we know of has explored the role of strong HR systems with regards to organizational change. Identifying mechanisms through which strong HR systems and employees' change reactions are linked is important because it helps us understand why HR systems that are perceived as consistent, widely understood, and distinctive lead employees to respond positively to change, and may inform broader theoretical models that examine the outcomes of strong HR systems. Moreover, this information is important in practice because it broadens the remit of the change agent role from one that focuses on HR content, to one that also designs HR systems to facilitate successful organizational change.

\section{Perceived HR System Strength and Coping with Change}

For a long time, HR scholars have emphasized HR's role as change agent (Storey, 1992; Tyson \& Fell, 1992). Ulrich's (1997) seminal work on the roles of the HR function has been particularly influential in that he charged the HR department to become "an agent of continuous transformation" (Ulrich, 1998: 125). Since then, numerous studies have highlighted different 
activities through which HR supports organizational change (see for an overview McDermott \& Conway, 2016). These activities fall into two general categories: those focused on the change content and those addressing change implementation. From a change content perspective, HR's tasks relate to redesigning HR practices (Alfes et al., 2010). This includes recruiting and selecting job candidates who can thrive in new work environments, designing performance management and reward systems to align individual and organizational goals, and providing learning opportunities to equip employees with needed skills and competencies. In terms of activities that support the implementation of change, studies have highlighted HR's responsibility in managing aspects of fairness (Schumacher, Schreurs, Van Emmerik, \& De Witte, 2016), communication and consultation (Schweiger \& Denisi, 1991) throughout the various stages of the change in order to positively influence employees' reactions to the change. Besides change content and change implementation, a third factor for change success, which has so far been ignored in conceptualizing HR's role as change agent, is the context within which change occurs (Armenakis \& Bedeian, 1999; Self et al., 2007). In this study, we focus on perceived HR system strength as one indicator of the change context.

Bowen and Ostroff (2004) suggested that the strength of HR systems is a function of three defining characteristics. The first is the extent to which the HR system is distinctive, referring to whether employees understand HR practices and deem them to be relevant. The second is the consistency of HR practices which drives the extent to which employees believe that HR practices trigger desired behaviors. Finally, consensus denotes perceptions of the level of agreement among employees about the types of behaviors that are expected of them. Strong HR systems are said to create a context which elicits collective employee attitudes and behaviors that are desired by the organization and therefore influence employees' ability to cope with the change. HR system 
strength complements the content of the HR system, and - provided that the HR system is aligned with the organizational strategy - fosters employees' collective understanding of the types of behaviors that are valued and rewarded by the organization. As a result, employees demonstrate these behaviors which over time leads to improved organizational performance. We leverage HR system strength theory to underpin our suggestion that HR system strength helps employees to cope with change.

Coping is described as a "person's cognitive and behavioral efforts to manage (reduce, minimize, master, or tolerate) the internal and external demands of the person-environment transaction that is appraised as taxing or exceeding the person's resources" (Folkman, Lazarus, Gruen, \& DeLongis, 1986: 572). Although research has identified various types of coping, we focus on problem-focused coping strategies (i.e., dealing with the stressor) because they constitute one of the most effective category of strategies employees use during times of organizational change (Judge, Thoresen, Pucik, \& Welbourne, 1999).

Although research has yet to examine HR system strength as a facilitator of employee coping with change, prior research hints at this relationship; a strong HR system is positively related to a host of positive attitudes and behaviors including improvisation behavior as a reaction to unforeseen circumstances (Rodrigues Ribeiro, Pinto Coelho, \& Gomes, 2011), citizenship behavior (Katou et al., 2014), and coworker assistance (Frenkel \& Yu, 2011), and negatively related to negative emotions and emotional exhaustion (Frenkel, Li, \& Restubog, 2012). Hence there is reason to believe that a strong HR system may aid in employee coping with change. We unravel this relationship both theoretically and empirically by examining two mediators which, we argue, simultaneously underpin it. In choosing our mediator variables, we were guided by literature which suggests that employees respond emotionally and cognitively to their work environment 
(George \& Jones, 2001; Kark Smollan, 2006). Emotions are immediate, short-term responses toward environmental stimuli, as indicated by the concept of positive affect (Gray \& Watson, 2001). In contrast, cognitions involve a more conscious evaluation of stimuli and a reflection about appropriate reactions (Scherer, 1999), which is exemplified in our study via perceived organizational support. In short, we examine the extent to which HR system strength works through the "heart" and the "mind" in aiding employees to cope with change.

\section{The Mediating Effect of State Positive Affect}

Emotion theory suggests that employees react to change in a way that helps them to understand the significance and relevance of the change for their own goals (Lazarus \& Folkman, 1984). Perceptions of a strong HR system facilitate the process of sense-making during change (Weick, 1995), so long as HR practices are aligned to the business strategy, and are communicated to employees as supportive of their goals and values. For instance, in a strong HR system, a new performance appraisal system might be introduced by the CEO and Head of HR as a way to align individual, departmental, and organizational goals, and these leaders might stress that a highperformance appraisal record will result in positive individual and organizational outcomes. Line managers would be supported by HR in delivering performance appraisals that are consistent with the values. In this way, employees agree among themselves about the intent of the performance appraisals, and understand what is expected of them. This reduces feelings of uncertainty, and enhances employees' sense of control, as strong HR systems give clear direction about the behaviors that are expected by organizations during change. For example, a strong HR system means that employees who behave in ways that are consistent with the organization's enduring values believe that those behaviors will result in positive recognition from the organization. When 
this cause (behavior) and effect (recognition) relationship is clear and employees believe that others in the organization agree on the behaviors that are valued and recognized by the organization, they feel in control of the situation and, given the positive relationship between a sense of control and positive affect (Troup \& Dewe, 2002), they report positive affective states. In a strong HR system, the organization exerts some control as it encourages people to behave in ways that are consistent with what the organization deems appropriate and worthwhile. At the same time, the predictability that the organization affords through a strong HR system provides employees with a sense of personal control and mastery, leading to higher levels of positive affect.

During times of change, employees also assess the meaning of the change for themselves (Lazarus, 1991; Lazarus \& Folkman, 1984). Specifically, employees make causal attributions about the outcomes of the change. Employees who believe that they are able to influence the outcomes of the change experience positive emotions (Liu \& Perrewé, 2005). As a strong HR system communicates consistent messages about the outcomes of specific behaviors, employees are more likely to attribute the outcome of decisions to their own actions, and feel a sense of independence and agency at work, leading to a positive affective state. Overall, perceptions of a strong HR system therefore create a framework that fosters employees' sense of personal control during organizational change, thus eliciting positive affect.

Consistent with this proposition, we further argue that positive affect increases employees' ability to cope with the change. This is because, according to broaden and build theory, positive emotions broaden individuals' momentary thought-action repertoires thereby motivating them to be willing to experience new situations (Fredrickson, 1998). Individuals with high levels of state positive affect therefore tend to perceive their situation in a more confident and optimistic way, and proactively search for positive aspects when evaluating their situation (Folkman \& Moskowitz, 
2000). Positive affect also provides a psychological break from negative emotions experienced during stressful events. By experiencing positive feelings individuals strengthen their psychological resources thereby improving their coping abilities (Lazarus, Kanner, \& Folkman, 1980). Several empirical studies support the notion that individuals with high levels of positive affect are better equipped to deal with stressful situations and use more effective coping mechanisms (Fredrickson \& Levenson, 1998). For example, a study by Harvey, Stoner, Hochwarter and Kacmar (2007) demonstrated that employees who participated in ingratiation and possessed high levels of positive affect were less affected by the negative consequences of abusive supervision. We therefore hypothesize that state positive affect mediates the effect of a strong HR system on employees' ability to cope with change.

Hypothesis 1a: Perceptions of HR system strength are positively related to employees' state positive affect.

Hypothesis 1b: State positive affect is positively related to employees' coping with organizational change.

Hypothesis 1c: State positive affect mediates the relationship between perceptions of HR system strength and employees' coping with organizational change.

\section{The Mediating Effect of Perceived Organizational Support}

Whereas positive affect is one route by which a strong HR system influences employee coping with change, a second avenue involves cognitive processes that derive from signals sent to employees via a strong HR system. Perceived organizational support captures employees' views about the nature of the relationship between them and the organization and is described as employees' beliefs about the extent to which their organization values their contributions and 
supports their wellbeing (Eisenberger et al., 1986). It is rooted in social exchange theory, which highlights the importance of norms of reciprocity within social relationships (Blau, 1964; Eisenberger et al., 1986). Social exchange theory posits that employees who receive socioemotional benefits from their organization, such as a high level of organizational support, feel obliged to reciprocate through positive attitudes and behaviors (Eisenberger, Armeli, Rexwinkel, Lynch, \& Rhoades, 2001).

When undergoing change, employees employ cognitive mechanisms to deal with the uncertainty that arises from changes in the work environment. Specifically, they interpret the change situation and evaluate the extent to which the change is likely to result in favorable outcomes for themselves (Cullen, Edwards, Casper, \& Gue, 2014). A strong HR system supports this process in that it sends a clear and consistent message about the behaviors that are expected from employees in the future (Bowen \& Ostroff, 2004). Open and transparent communication as a key feature of a strong HR system is particularly important during change and should be adapted to the different phases that employees experience, including denial, resistance, exploration, and acceptance (Elrod \& Tippett, 2002). Communication should focus on giving information about the background of the change and the implications for teams, finding answers to oftentimes emotional reactions and feedback from employees, explaining how employees' roles and responsibilities might change and providing access to support documents which guide employees through the change. Communication can be delivered face-to-face between senior management and employees (i.e. townhall meetings, road shows), in conversations with line managers (i.e. workshops, one-toone conversations), and also virtually (i.e. emails; group chats; blogs). Overall, HR's communication increases perceptions of support throughout the change and enhances individuals' sense that the organization is committed to them and treats them with respect (Rhoades \& 
Eisenberger, 2002). Employees form more realistic ideas of their future roles in the organization and, given that a strong HR system is distinctive and agreed upon by all members of the organization, are able to interpret the change situation more accurately. A strong HR system therefore reduces uncertainty and increases employees' perceptions that the organization cares about them and takes the necessary steps to support them in the change initiative. We therefore expect a positive relationship between perceived strength of the HR system and employees' perceptions of their organization's support.

Employees' perceptions of organizational support influence their ability to cope with change for two reasons. First, employees who feel supported by their organization are more likely to reciprocate by supporting the organization in its change program (Blau, 1964), especially if the organization is transparent in communicating information about the change. Employees therefore work toward the organization's new goals because they believe that the organization values their change efforts and will repay them for their contributions in the future (Shin, Taylor, \& Seo, 2012). Second, organizational support shapes employees' view of the change. A high level of organizational support implies a belief that the organization considers employee goals and encourages employee participation in the change program. Their input into the change enhances the view that they can master the change. Hence, perceptions of organizational support lead to the mobilization of coping strategies (Shin et al., 2012). Therefore, we hypothesize that perceived organizational support mediates the effect of perceptions of a strong HR system on employees' ability to cope with the change.

Hypothesis 2a: Perceptions of HR system strength are positively related to perceived organizational support. 
Hypothesis 2b: Perceived organizational support is positively related to employees' coping with organizational change.

Hypothesis 2c: Perceived organizational support mediates the relationship between perceptions of HR system strength and employees' coping with organizational change.

\section{The Outcome of Coping with Change: Change-Supportive Behavior}

Ample research shows that the success or failure of a change program depends on employee behaviors during the change (Whelan-Berry, Gordon, \& Hinings, 2003). Specifically, employee resistance hinders the successful completion of a change program, whereas change-supportive behavior - defined as "actions employees engage in to actively participate in, facilitate, and contribute to a planned change initiated by the organization" (Kim, Hornung, \& Rousseau, 2011: 1665 ) - enables an organization to achieve its desired change outcomes (Balogun, Hope-Hailey, \& Gustafsson, 2015). This is because organizations rely on their staff to engage in behaviors that ultimately contribute to the successful completion of change (i.e. positively communicate the change to one another, participate in work groups or champion new training methods) (Jones, Jimmieson, \& Griffiths, 2005).

While employees who effectively cope with the change put forth cognitive and behavioral efforts to personally manage the change (Lazarus \& Folkman, 1984), change-supportive behaviors are discretionary and outward-looking behaviors that we argue derive, at least in part, from a person's ability to cope with change. Hence, while coping implies that employees adjust to new situations, change-supportive behaviors result in actual behaviors in that employees make an active contribution to the change (Kim et al., 2011). Indeed, those who cope with change are more likely to promote the change and try to convince other organizational members of the appropriateness of 
the change. This is because employees who have confidence in their ability to cope with new situations cognitively appraise the change situation differently (Rafferty \& Griffin, 2006). They assess the change in a more positive way and perceive the uncertainty surrounding the change as less stressful and threatening, hence, they possess additional psychological resources which put them in a position where they are better equipped to support the change (Cunningham et al., 2002).

Despite the intuitive relationship between coping with change and change-supportive behavior, very little published research has examined this relationship. One exception is a study on change in a professional association related to public housing by Wanberg and Banas (2000) that found that change-related self-efficacy, which is conceptually similar to coping with change, was positively related to the extent to which employees accepted and supported organizational change. Moreover, in an analysis of change in a Canadian hospital, Cunningham et al. (2002) demonstrated that confidence in the ability to cope with change was positively related to a host of positive change behaviors, such as readiness for change and participation in the change. While both studies focused on changes that were initiated by their respective organizations, this focus does not take into account changes that may be imposed externally such as those imposed by governments. We therefore build on previous research by suggesting that individuals' ability to cope will influence their change-supportive behavior when faced with a large-scale transformational change that transcends the borders of their own organization. In addition, our study builds on prior work by examining state positive affect and perceived organizational support as antecedents of changesupportive behavior that are mediated via coping with change. Drawing from broaden and build theory (Fredrickson, 1998), we argue that, as positive affect improves employees' ability to cope, they are equipped with additional psychological resources, which prompt them to generate new ways of thinking and pursue novel behaviors. Following social exchange theory (Blau, 1964) we 
suggest that employees who feel supported by their organization during change aim to maintain a positive relationship with the organization and reciprocate by supporting the change through their behaviors. In other words, we empirically examine the entirety of the model depicted in Figure 1. Hence, we offer our final hypothesis:

Hypothesis 3: Coping with organizational change is positively related to employees' engagement in change-supportive behavior and mediates the relationship between state positive affect, perceived organizational support, and change-supportive behavior.

\section{Methods}

\section{Respondents and Procedures}

The data were collected within a large territorial police force in the UK. At the time of the data collection, the organization was in the middle of a major transformation, which was initiated by the UK government in an effort to deal with the economic crisis that began in 2008. Public sector organizations were asked to save costs of $30 \%$ over a period of four years, resulting in a considerable reduction of services offered to the public and a significant loss of jobs across all areas of the public sector (Truss, 2013). For the police force, an independent review was commissioned by the UK government in October 2010 to evaluate pay and conditions of service for police officers and staff. The aim of the review was to make recommendations with regards to the modernization of the police pay system and the provision of a more efficient service (see Winsor, 2012 for the final review). The review suggested a different pay structure taking into account qualifications, skills and performance that would lead to cost savings of $£ 3$ billion. The research context therefore offers an ideal setting for analyzing the consequences of HR system strength for individual attitudes and behaviors during change. 
We interviewed the Head of Organizational Development about the implications of these changes for the organization from which our sample was drawn. He explained that the rationale for the change was clearly communicated through a variety of communication mechanisms so that employees were aware that the change was imposed through government action. These included an initial event to inform employees about the government's rationale and vision behind the change and the implications of the change for employment conditions in the police force, regular emails from the management team, town hall meetings, newsletters, manuals and team meetings. Employees therefore very likely made external attributions about the reasons behind the change rather than attributing it to a choice made by the organization's management (Koys, 1988). The change involved the restructuring of several departments and changes in HR practices, such as the reduction of training budgets, recruitment freezes and voluntary redundancies. The Head of Organizational Development also advised that the nature of the organization and the ethos of the policing profession, together with the change being attributed externally, ensured that the expected behaviors from the workforce remained stable.

A work group consisting of HR and Organizational Development managers was set up at the police force to facilitate the administration of the survey. All 1901 employees were sent a link to an online questionnaire and encouraged to participate in the survey within three weeks. Employees were informed about the purpose of the study and its confidentiality and given time to complete the survey at work. A reminder email was sent two weeks after the survey was issued. 704 employees completed the questionnaire, yielding a response rate of $37 \%$, which exceeds the average response rate of $35.7 \%$ in organizational research such as this (Baruch \& Holtom, 2008; Kaplowitz, Hadlock, \& Levine, 2004). The sample includes police officers $(n=304)$ and staff $(n=228)$ covering a range of business functions such as IT, HR and finance. The sample was 59.4 
percent male; the average age was 41.89 years (s.d. $=8.61$ ); and employees had worked an average of 17.68 years in the public sector $($ s.d. $=9.60)$.

Although our response rate is acceptable considering that participants were contacted by email alone (Kaplowitz et al., 2004), we employed two established methods for estimating nonresponse bias and ascertain whether the profile and attitudes of the non-respondents differed significantly from the employees who took part in our survey. First, we compared our sample to the overall known population of the territorial police force (Armstrong \& Overton, 1977). We found that the profile of the police officers was very similar to the overall profile of the police force on key criteria such as gender, rank and ethnicity. Similarly, the staff profile corresponded very closely to the overall staff profile employed at the police force with regards to their gender and employment status (Home Office, 2012).

Second, we tested for systematic bias between our respondents and those who decided not to participate in our survey using an established procedure recommended by Armstrong and Overton (1977). Specifically, we sorted our data according to the date and time of the respondents' survey submission. The first 50 percent of the respondents were categorized as early respondents, while the other 50 percent were categorized as late respondents. We compared these two groups across all study variables using a series of independent samples $t$-tests. Individuals who responded to our survey early did not differ significantly from those who responded later on any of the study variables. Based on the assumption that late respondents tend to be similar to non-respondents (Armstrong \& Overton, 1977), we are confident that our results are not unduly influenced by nonresponse bias and that the profile and attitudes of non-respondents are similar to the profile of those employees who participated in our study.

\section{Measures}


Responses to all Likert-type scale items ranged from 1 (Strongly Disagree) to 5 (Strongly Agree), unless otherwise noted. Items were averaged to form each multiple-item measure. In the instructions, participants were asked to think of the current organizational change when answering the change-related questions. A full list of items is provided in Appendix A.

Perceptions of HR system strength. We measured perceptions of HR system strength with a 9item scale developed by Frenkel, Li and Restubog (2012). The measure asked participants to assess the extent to which the HR system in their organization was characterized by the three facets of a strong HR system: distinctiveness ("HR practices here make me feel much more confident in my ability to do my job well"), consistency ("HR policies here are clearly communicated to employees") and consensus ("Managers here agree on how to implement HR policies"). Consistent with prior research, the three subscales were combined into an overall measure of HR system strength (Frenkel et al., 2012). The reliability coefficient was .90 .

State positive affect. In line with previous research exploring employees' emotional responses during organizational change (e.g., Shin et al., 2012), respondents were asked to rate the extent to which they experienced state positive affect at work during the change on a scale from 1 ("not at all") to 5 ("extremely") using the 10 positive affect states from the Positive and Negative Affectivity Scale (PANAS; Watson, Clark, \& Tellegan, 1988). Example items are "strong" and "enthusiastic". The reliability coefficient was .93 .

Perceived organizational support. Perceived organizational support was measured with four items taken from the Survey of Perceived Organizational Support (Eisenberger et al., 1986). This shortened version has been used in previous studies (e.g., Alfes, Shantz, Truss, \& Soane, 2013) and has shown high reliability. Participants responded to items such as, "My organization shows a lot of concern for me." The reliability coefficient was .93 
Coping with organizational change. Coping with organizational change was measured with eight out of the twelve items from the scale developed by Judge et al. (1999). The eight items were selected after conversation with the organization's work group to make sure that the items were understandable and relevant to the study's participants. Three items were removed because their focus was on how the organization handles change, rather than how individuals cope with change (e. g., "The rapid changes that have been occurring in this company are sometimes beyond the abilities of those within the company to manage"), because the change was introduced by the government rather than the organization itself. A fourth item ("I have been a leader of transformation efforts within this company") was removed, as the work group explained that employees had not been given ample opportunities in the past to lead transformational changes. An example of an included item is, "When changes happen in my organization, I react by trying to manage the change rather than complain about it.” The reliability coefficient was .72 .

Change-supportive behavior. Employees were asked to rate the extent to which they engaged in change-supportive behavior using six of the seven items of the pro-change behavior scale developed by Giangreco and Peccei (2005). We excluded the item "I make considerable effort so that my subordinates understand the change", as the majority of employees did not supervise other employees. An example item is, "I co-operated actively to realize the change". The reliability coefficient was .93.

\section{Results}

Table 1 presents the scale reliabilities, means and standard deviations, and inter-scale correlations for all study variables. The highest correlation (.58) occurs between HR system strength and perceived organizational support, which although is considered as a strong correlation 
(Cohen, 1988) is below .90, which is an indication of substantial collinearity (Hair, Black, Babin, \& Anderson, 2009).

Insert Table 1 about here

\section{Measurement Models}

As all measures were collected from a single source, a series of confirmatory factor analyses were conducted to assess the potential influence of common method bias and to establish the discriminant validity of the scales. A full measurement model was initially tested in which the indicators for all variables were allowed to load onto their respective factors. All factors were allowed to correlate. Five fit indices were calculated to determine how the model fitted the data (Hair et al., 2009). For the $\chi^{2} / \mathrm{df}$, values less than 2.5 indicate a good fit and values less than 5 an acceptable fit (Arbuckle, 2006). For the incremental fit index (IFI) and the comparative fit index (CFI), values greater than 90 represent a good model fit (Bentler, 1990; Bentler \& Bonett, 1980). For the Root Mean Square Error of Approximation (RMSEA) and the Standardized Root Mean Square Residual (SRMR), values less than .08 indicate an acceptable model fit (Browne \& Cudeck, 1993; Hu \& Bentler, 1998).

The five-factor model showed a good model fit $\left(\chi^{2}=2046 ; \mathrm{df}=618 ; \mathrm{IFI}=.91 ; \mathrm{CFI}=.91\right.$; RMSEA $=.06 ;$ SRMR $=.06)$. Next, sequential $\chi^{2}$-difference tests were carried out. Specifically, the full measurement model was compared to nine alternative nested models as shown in Table 2. Results of the measurement model comparison revealed that the model fit of the alternative models was significantly worse compared to the full measurement model (all at $p<.001$ ). Finally, we used the CFA marker approach as described by Williams, Hartman and Cavazotte (2010) and added a theoretically unrelated marker variable (4-item measure of beneficiary contact, Grant, 2012) to our 
theoretical model. Including this variable enabled us to assess the extent to which our results were influenced by common method variance, as the shared variance between a marker and the other substantive constructs indicates the magnitude of common method variance in a study (Richardson, Simmering, \& Sturman, 2009; Williams et al., 2010). Results of the reliability decomposition revealed that the method components accounted for between $0.07 \%$ and $5.00 \%$ of the reliability values of the latent constructs, which is below the values range of $12.5 \%$ to $19.7 \%$ in the study by Williams et al. (2010). Overall, this suggests that the variables in this study are distinct.

Insert Table 2 about here

\section{Test of Hypotheses}

We employed latent variable structural equation modelling using Maximum Likelihood estimation in AMOS 23.0 (Arbuckle, 2006) to test our theoretical model. To examine our mediated relationships, we followed the steps outlined by Mathieu and Taylor (2006). The procedure compares three alternative models: saturated, direct effects, and indirect effects. For the saturated model, paths were estimated from the independent variable (HR system strength) to affect, perceived organizational support, coping and change-supportive behavior, from affect and perceived organizational support to coping and change-supportive behavior, and a direct path from coping to change-supportive behavior. The saturated model provided a good fit for the data $\left(\chi^{2}=\right.$ 2046; $\mathrm{df}=620 ; \mathrm{IFI}=.90 ; \mathrm{CFI}=.90 ; \mathrm{RMSEA}=.06 ; \mathrm{SRMR}=.08)$.

For the direct effects model, direct paths were estimated from HR system strength to changesupportive behavior, whereas no path led to or stemmed from the mediators. The indirect effects model estimated direct paths from HR system strength to affect and perceived organizational 
support, direct paths from affect and perceived organizational support to coping and a direct path from coping to change-supportive behavior. The direct effects model and the indirect effects model were both nested within the saturated model, which enabled us to use $\chi^{2}$-difference tests to compare the statistical fit of the three models. Hence, the $\chi^{2}$-difference between the direct effects model and the saturated model, as well as between the indirect effects model and the saturated model, were tested for significance while accounting for the change in degrees of freedom between the models. The data are shown in Table 3 .

Insert Table 3 about here

The direct effects model showed a weak model fit $\left(\chi^{2}=2682 ; \mathrm{df}=628 ; \mathrm{IFI}=.86 ; \mathrm{CFI}=.86\right.$; $\operatorname{RMSEA}=.07 ;$ SRMR $=.20)$, and differed significantly from the saturated model $\left(\Delta \chi^{2}(8)=636\right.$, $p<.001)$. This indicates that HR system strength has a significant direct relationship with one of the mediators, or that one of the mediators is significantly related with change-supportive behavior, and reinforces the importance of the mediator variables in our model. The indirect effects model showed a very good model fit $\left(\chi^{2}=1474 ; \mathrm{df}=624 ; \mathrm{IFI}=.92 ; \mathrm{CFI}=.92 ; \mathrm{RMSEA}=.06 ;\right.$ SRMR $=$ $.08)$ and showed a significantly better fit compared to the saturated model $\left(\Delta \chi^{2}(4)=572, p<.001\right)$. This finding supports a fully mediated model, as hypothesized in our theoretical model.

Our results demonstrate that HR system strength was positively related to state positive affect $(\beta=.26, p<.001)$ and perceived organizational support $(\beta=.61, p<.001)$; thus hypotheses 1a and 2a were supported. State positive affect $(\beta=.43, p<.001)$ and perceived organizational support ( $\beta$ $=.20, p<.001$ ) were positively and significantly related to coping, providing evidence in support of hypotheses $1 \mathrm{~b}$ and $2 \mathrm{~b}$. We examined the significance of indirect effects using the product-of- 
coefficients approach combined with bootstrapping in AMOS 23.0, using 5,000 bootstrap samples and the bias corrected 95\% confidence intervals (CIs). The indirect effects of HR system strength on coping via affect and perceived organizational support were both significant with $\mathrm{CI}=[.08 ; .17]$, $p<.001$ for affect and $\mathrm{CI}=[.17 ; .29], p<.001$ for perceived organizational support. In addition, coping was significantly and positively related to change-supportive behavior ( $(\beta=.69, p<.001)$. Moreover, the indirect effects of affect $(\mathrm{CI}=[.29 ; .41], p<.001)$ and perceived organizational support $(\mathrm{CI}=[.19 ; 33], p<.001)$ on change-supportive behavior via coping were both significant.

This implies that the relationship between HR system strength and coping was mediated by positive affect and perceived organizational support and that the relationship between positive affect, perceived organizational support and change-supportive behavior was mediated by coping, supporting hypotheses $1 \mathrm{c}, 2 \mathrm{c}$, and 3 . The standardized estimates of the final model are represented in Figure 1.

Insert Figure 1 about here

\section{Discussion}

The overriding purpose of this study was to broaden the remit of the role of HR as change agent. To do so, we built and tested a model to demonstrate that employee perceptions of HR system strength constitute an important contextual factor which positively influences employees' reactions toward change. The results of our empirical analyses showed that employee perceptions

of HR system strength are crucial during periods of change because they elicit both cognitive and affective processes that encourage problem-focused coping with change, which in turn leads 
employees to actively support the change. Our study therefore contributes to the literature on HR and organizational change in several ways.

Change management research focuses on change content and change implementation to assess employee reactions toward change and identify successful change management strategies (Armenakis \& Bedeian, 1999). Our first contribution is therefore to the small, but growing number of studies which have explored change by demonstrating that the context in which employees are embedded plays an important role in influencing their reactions to change (Herold et al., 2007; Rafferty \& Restubog, 2017). Specifically, we demonstrated that organizations which have developed and implemented a strong HR system create a framework that guides employees through the change. It is noteworthy that perceptions of HR system strength can be managed by the organization. This is especially important, given that the particular change in question in our study organization was one over which the organization had little input or control because it was externally imposed. This suggests that researchers aiming to understand the drivers of successful change need to expand their theoretical models by including the impact of contextual factors on employees' reactions to change. Our findings might also help to explain why change programs that are carefully designed still fail since features of the organizational context that have a distal connection to the change efforts, such as the HR system, are often ignored and may hinder employees' reactions to change.

Second, we contribute to literature on HR's role in facilitating change and, in doing so, we have extended the conversation regarding the remit of the role of HR as change agent. Indeed, previous research has established that the HR department has an important role to play in supporting organizational change (e.g., Alfes et al., 2010; Caldwell, 2001; Conway \& Monks, 2008; Ulrich, 1997). However, prior research has suggested that HR's change agent role involves change content 
or change implementation (e.g., Alfes et al., 2010; Brown, Kulik, Cregan, \& Metz, 2017; Kim \& Ryu, 2011; Long et al., 2013). In contrast, our findings suggest that, aside from making a contribution via these two facets of change, HR can also contribute to successful change by ensuring that the context is change-ready. Researchers studying the role of HR during change therefore need to revise the pathways of how HR affects change so that they focus not only on the content and implementation of change, but also the context of change.

The present study makes an important contribution to the literature on HR system strength. According to Bowen and Ostroff (2004), employees' perceptions of a strong HR system lead to a collective sense of what is valued in the organization, which ultimately leads to improved organizational performance. While previous studies have demonstrated that the shared understanding of HR practices has a positive impact on employees' attitudes toward their work and their organization (Frenkel et al., 2012; Li et al., 2011), our findings show that a strong HR system also has positive consequences during organizational change. We therefore extend Bowen and Ostroff's framework by theoretically articulating and empirically showing that the behavioral expectations that are inherent in a strong HR system provide guidance to employees during times of organizational change.

Our study also contributes to the literature by identifying and simultaneously testing two mechanisms through which perceptions of HR system strength are related to coping with organizational change. We found that perceptions of a strong HR system are positively associated with employees' emotional and cognitive reactions during change. This finding supports previous change management literature (Kark Smollan, 2006). Specifically, a strong HR system has the potential to speak to employees' "heart" in that it triggers positive affective responses to the change. It also speaks to employees' "minds" leading them to more favorably evaluate the change 
situation, the support they receive from the organization, and the implications for themselves. The results show that both mechanisms act independently, and contribute equally to understanding the relationship between HR system strength and coping with organizational change. Overall, this deepens our understanding of how HR systems can exert a positive influence on employees.

Of additional interest in our results was that staff members reported more positive attitudes toward the change compared to police officers (Table 1). This is somewhat counterintuitive, as staff members faced the risk of redundancy, whereas officers did not. There are at least two reasons that might explain this effect. First, the organization's Head of Organizational Development stated that police officers were more strongly affected by the review of pay and conditions compared to staff members. Hence, the more negative attitudes toward the change might, in part, have been influenced by discussions at a national level. Second, the recruitment freeze may have had a greater negative impact on the workload of officers, thereby affecting their ability to cope with the change. The difference in change attitudes between police officers and staff could also suggest that the HR system is stronger in a more stable work environment, where there is no change in supervisors and team composition due to shift patterns. Further research could investigate this by analyzing the implications of an HR system on employee change reactions across different job types and positions.

\section{Directions for Future Research}

The present study opens up a new avenue of research for scholars interested in the role of HR in facilitating organizational change. For instance, future HR research could consider how change content (i.e., functional HR practices), change implementation (i.e. generating employee support throughout the different steps of the change) and change context (i.e., a strong HR system) interact 
to positively influence employees' change reactions. Studies might explore whether it is enough for HR's change agent role to focus on one facet of change, or whether HR's contribution to successful change management can be strengthened further by focusing on content, implementation and context simultaneously.

It may also be fruitful to examine the implications of a strong HR system that is not positively received by employees. It is plausible that in some organizations, employees fail to "buy-into" the system or its values, even if the HR system is perceived to be strong. Qualitative research may be best suited to investigate this scenario to determine whether a weak versus a strong system that is misaligned with employees' own values or expectations produces different outcomes. If a quantitative approach is taken, this may require additional scale development, as the scale that we used here to measure HR system strength (see Appendix A) connotes a positive appraisal of HR, and research that examines system strength vis-à-vis HR content should use a more neutral HR strength measure.

Future research could also examine the extent to which individual differences, such as a person's positive self-concept, moderate the relationships found in the present study, since prior research has established that an employee's positive self-concept also plays a role in coping with and responding to organizational change (e.g., Judge et al., 1999; Ritz, Shantz, Alfes, \& Arshoff, 2012). A question in this regard is whether a strong HR system or a positive self-concept suffices for employees to feel positive about a change or whether individual and organizational-level factors need to be combined to generate support for a change.

The dependent variable in our model is change-supportive behavior. However, the anticipated change outcome is likely to be influenced by a host of additional factors (Beer, Eisenstat, \& Spector, 1990). We therefore encourage researchers to explore the conditions under which positive 
change attitudes and behaviors translate into a successful change outcome. For example, a lack of coordination and planning might prevent change-supportive behavior from manifesting in desirable change outcomes. In contrast, establishing supportive structures, guidelines and policies is likely to have a positive impact on the extent to which change-supportive behavior translates into positive change outcomes. Research which bridges levels of analysis to explore how individual-level change attitudes and behaviors aggregate to company-level change success is specifically very welcome.

Another important question that stems from our work is: How can organizations bring about a strong HR system? A potential route to ensuring a strong HR system is to focus on developing HR capabilities. Khatri, Gupta and Varma (2017) suggested that HR capabilities consist of three dimensions: (1) a CEO who sets a clear strategy and supports the HR function; (2) a Head of HR who understands the business and enacts effective leadership behaviors both within the HR department and across other departments; and (3) the professionalism and competencies of HR staff who carry out key HR activities. Khatri et al. (2017: 676) hinted at the association between HR capabilities and system strength in suggesting that "HR capabilities are necessary to create a 'strong HR system' and reduce the gap between intended and implemented HR practices and systems" and, although they did not test this assumption, they found that HR capabilities have both a direct and indirect effect (through proactivity) on quality of patient care. Research that integrates the findings from Khatri et al. (2017) and of our study would provide invaluable information for future theory development and practice. On a broader level, we welcome research which takes a dynamic capabilities perspective (Teece, Pisano, \& Shuen, 1997) to provide a deeper understanding of how HR can contribute to organizational competitiveness in highly volatile environments. 
Finally, future research could explore the extent to which the impact of a strong HR system on employee reactions varies during change. For example, a strong HR system might be more beneficial at the start rather than toward the end of a change initiative. Moreover, the importance of a strong HR system might differ depending on the scope of the change. The data in our study were taken from a large-scale, transformative change program, and results might alter when looking at smaller and more incremental changes. Qualitative case studies across several organizations that vary in these ways would shed light on these questions.

\section{Practical Implications}

Spurred on by Ulrich's assertion that HR should become a "change agent", HR practitioners have attempted to take a more active role in the management of change to support organizations in transforming their businesses. Anecdotal evidence, however, shows that many HR departments have not fully realized this potential. In fact, upon reading this article, some practicing managers may question its basic premise - does HR in reality play an important role in change? This is because the popular press is rife with criticism about HR itself being a major source of resistance to change (Cappelli, 2015; Hammonds, 2005). One reason for this might be that HR departments have interpreted their change agent role as one that is focused on change content (i.e., changing HR practices) and change implementation, and largely neglected a systematic examination of the change context as part of a successful change management strategy. Our results indicate that HR departments that are involved in change management should take into consideration how contextual factors, such as a strong HR system, influence employees' reactions toward change. In order to exert its desired effect, a strong HR system needs to be complemented by HR practices which are aligned with the company's strategic objectives. Hence, HR managers need to ensure a 
fit between the content of their HR system and the business strategy, and also evaluate whether the HR system is sufficiently distinctive, coherent, and widely communicated to enhance individuals' ability to cope with, and increase their willingness to support organizational change.

Another potential reason that HR is not seen as a driver of change is that many activities that were once within HR's remit have been devolved to the line. This presents a new challenge for HR professionals to communicate with employees about required changes, how they align with the organization's core values, and support the business strategy. HR professionals need to ensure that line managers understand the HR practices in their organization and implement them accordingly. A strong HR system depends on a consistent application of HR practices across the organization. Hence, HR professionals need to provide information to managers about the purpose of the HR practices and the individual behavior that they should encourage.

A third reason why HR might be seen as the resistor, rather than the driver of change, derives from the nature of a strong HR system to begin with. Creating a strong HR system requires a compelling vision, intricate communication strategies, careful attention to interconnections among HR practices, and commitment to sustaining the system. In such a tightly knit system, change may ironically become increasingly difficult. It is therefore important to weave flexibility and employee agility into the fabric of a strong HR system so that businesses can balance strength with change.

A final cautionary note about why HR is seen as a source of dissatisfaction during change relates to the challenge of finding an adequate balance between offering support, while avoiding unwarranted feelings of entitlement among employees. For instance, an annual summer party which is organized as a way to celebrate change success may, over time, be viewed as an entitlement, and if it is removed, employees become disgruntled. HR managers therefore need to communicate in an open and transparent manner about the types of emotional and financial support 
that the organization can give during times of change, and also be specific about whether those forms of support will be available after the change is completed. HR departments should work together with the organization's top management to ensure their continuous level of commitment for the support that has been promised to employees. In situations where employees express excessively high feelings of entitlement, HR managers need to foster an open dialog to understand where the high levels of entitlement originated, but also to demonstrate the level of support that the organization can realistically give to employees in the future.

\section{Limitations}

Although our research provides interesting insights into the role of a strong HR system during change, our results should be assessed against the background of the limitations inherent in our study. First, we collected data at one point in time, which limits the conclusions that can be made regarding the causal order of the relationships. We therefore welcome longitudinal research designs to substantiate the causality of our hypotheses.

Second, we relied on individuals' self-reports on all variables of our model, which raises the concern of common method bias. Common method bias describes a systematic variation in an observed variable which is based on the method used to collect the data (Spector, Rosen, Richardson, Williams, \& Johnson, 2017). Hence, some of the correlations in our results may be due to systematic measurement error; in this way, correlations may occur because of how we collected our data, rather than the 'true' underlying relationships among the constructs of interest (Podsakoff, MacKenzie, Jeong-Yeon, \& Podsakoff, 2003). Notably, however, the statistical analyses revealed that common method bias did not cause a major concern in our study. Moreover, self-report measures might be the most valid measurement method for most of our variables, as 
individuals are best placed to report how they perceive the HR system, the support they receive from the organization, and their attitudes during the change. Nevertheless, we encourage future researchers to collect data from multiple sources to investigate our findings further.

Third, our study took place in a particular change context. Our sample was undergoing a major transformation, which was initiated by the UK government as part of a larger cost saving program across the public sector. Hence, our findings might differ from findings in organizations where change is initiated by the organization.

Finally, our theoretical model is by no means exhaustive. For instance, there are broader contextual factors including new skill mixes, productivity mandates, and product/service innovations which may interrelate with the HR context to influence change outcomes. The theoretical and empirical work presented here therefore marks the beginning of developing a more elaborate model to explain how the potential of HR can be leveraged within a wider change context to facilitate successful change outcomes.

\section{Conclusion}

Our study sheds light on HR's role as change agent by considering the positive implications of the change context for employees' overall attitudes toward change. Focusing on HR system strength theory, we developed and tested a model which links employees' perceptions of HR system strength to employees' coping with, and subsequent responses to, organizational change. In line with central propositions of emotion theory and social exchange theory, this study shows that a strong HR system enhances employees' ability to cope with change because it simultaneously activates positive emotions and the belief that the organization supports and cares about the wellbeing of employees. Hence, an organization's HR system strength should be taken 
into account when implementing a change initiative as the messages sent through HR practices have an impact on employee attitudes and behaviors during change. 


\section{References}

Alfes, K., Shantz, A. D., Truss, C., \& Soane, E. C. (2013). The link between perceived human resource management practices, engagement and employee behaviour: A moderated mediation model. The International Journal of Human Resource Management, 24(2), 330-351.

Alfes, K., Truss, C., \& Gill, J. (2010). The HR manager as change agent: Evidence from the public sector. Journal of Change Management, 10(1), 109-127.

Arbuckle, J. L. (2006). Amos (version 7.0) [computer program]. Chicago: SPSS.

Armenakis, A. A., \& Bedeian, A. G. (1999). Organizational change: A review of theory and research in the 1990s. Journal of Management, 25(3), 293-315.

Armstrong, J. S., \& Overton, T. S. (1977). Estimating nonresponse bias in mail surveys. Journal of Marketing Research, 14(3), 396-402.

Balogun, J., Hope-Hailey, V., \& Gustafsson, S. (2015). Exploring strategic change (4 ed.). Harlow: Pearson.

Baruch, Y., \& Holtom, B. C. (2008). Survey response rate levels and trends in organizational research. Human Relations, 61(8), 1139-1160.

Beer, M., Eisenstat, R. A., \& Spector, B. (1990). Why change programs don't produce change. Harvard Business Review, 68(6), 158-166.

Bentler, P. M. (1990). Comparative fit indexes in structural models. Psychological Bulletin, 107(2), 238-246. 
Bentler, P. M., \& Bonett, D. G. (1980). Significance tests and goodness of fit in the analysis of covariance structures. Psychological Bulletin, 88(3), 588-606.

Blau, P. M. (1964). Exchange and power in social life. New York: Wiley.

Bowen, D. E., \& Ostroff, C. (2004). Understanding HRM-firm performance linkages: The role of the "strength" of the HRM system. Academy of Management Review, 29(2), 203-221.

Brown, M., Kulik, C. T., Cregan, C., \& Metz, I. (2017). Understanding the change-cynicism cycle: The role of HR. Human Resource Management, 56(1), 5-24.

Browne, M. W., \& Cudeck, R. (1993). Alternative ways of assessing model fit. In K. A. Bollen \& J. S. Long (Eds.), Testing structural equation models (pp. 136-162). Newbury Park: Sage.

Caldwell, R. (2001). Champions, adapters, consultants and synergists: The new change agents in HRM. Human Resource Management Journal, 11(3), 39-52.

Cappelli, P. (2015). Why we love to hate HR...And what HR can do about it. Harvard Business Review, 93(7/8), 54-61.

Choi, M. (2011). Employees' attitudes toward organizational change: A literature review. Human Resource Management, 50(4), 479-500.

Cohen, J. W. (1988). Statistical power analysis for the behavioral sciences (2 ed.). Hillsdale: Lawrence Erlbaum Associates.

Conway, E., \& Monks, K. (2008). HR practices and commitment to change: An employee-level analysis. Human Resource Management Journal, 18(1), 72-89. 
Cullen, K. L., Edwards, B. D., Casper, W. C., \& Gue, K. R. (2014). Employees' adaptability and perceptions of change-related uncertainty: Implications for perceived organizational support, job satisfaction, and performance. Journal of Business and Psychology, 29(2), 269-280.

Cunningham, C. E., Woodward, C. A., Shannon, H. S., MacIntosh, J., Lendrum, B., Rosenbloom, D., et al. (2002). Readiness for organizational change: A longitudinal study of workplace, psychological and behavioural correlates. Journal of Occupational and Organizational Psychology, 75(4), 377-392.

Eisenberger, R., Armeli, S., Rexwinkel, B., Lynch, P. D., \& Rhoades, L. (2001). Reciprocation of perceived organizational support. Journal of Applied Psychology, 86(1), 42-51.

Eisenberger, R., Huntington, R., Hutchison, S., \& Sowa, D. (1986). Perceived organizational support. Journal of Applied Psychology, 71(3), 500-507.

Elrod, P. D., \& Tippett, D. D. (2002). The "death valley" of change. Journal of Organizational Change Management, 15(3), 273-291.

Folkman, S., Lazarus, R. S., Gruen, R. J., \& DeLongis, A. (1986). Appraisal, coping, health status, and psychological symptoms. Journal of Personality \& Social Psychology, 50(3), 571-579.

Folkman, S., \& Moskowitz, J. T. (2000). Positive affect and the other side of coping. American Psychologist, 55(6), 647-654.

Fredrickson, B. L. (1998). What good are positive emotions? Review of General Psychology, 2(3), 300-319. 
Fredrickson, B. L., \& Levenson, R. W. (1998). Positive emotions speed recovery from the cardiovascular sequelae of negative emotions. Cognition \& emotion, 12(2), 191-220.

Frenkel, S. J., Li, M., \& Restubog, S. L. D. (2012). Management, organizational justice and emotional exhaustion among Chinese migrant workers: Evidence from two manufacturing firms. British Journal of Industrial Relations, 50(1), 121-147.

Frenkel, S. J., \& Yu, C. (2011). Managing coworker assistance through organizational identification. Human Performance, 24(5), 387-404.

George, J. M., \& Jones, G. R. (2001). Towards a process model of individual change in organizations. Human Relations, 54(4), 419-444.

Giangreco, A., \& Peccei, R. (2005). The nature and antecedents of middle manager resistance to change: Evidence from an Italian context. International Journal of Human Resource Management, 16(10), 1812-1829.

Grant, A. M. (2012). Leading with meaning. Beneficiary contact, prosocial impact, and the performance effects of transformational leadership. Academy of Management Journal, 55(2), $458-476$.

Gray, E. K., \& Watson, D. (2001). Emotions, mood and temperament: Similarities, differences, and a synthesis. In R. Payne \& C. Cooper (Eds.), Emotions at work: Theory, research and applications for management (pp. 21-43). Chichester: John Wiley and Sons.

Hair, J. F., Black, W. C., Babin, B. J., \& Anderson, R. E. (2009). Multivariate data analysis (7 ed.). New Jersey: Pearson Prentice Hall. 
Hammonds, K. H. (2005). Why we hate HR. Fast Company Magazin, August 2005, https://www.fastcompany.com/53319/why-we-hate-hr.

Harvey, P., Stoner, J., Hochwarter, W., \& Kacmar, C. (2007). Coping with abusive supervision: The neutralizing effects of ingratiation and positive affect on negative employee outcomes. The Leadership Quarterly, 18(3), 264-280.

Herold, D. M., Fedor, D. B., \& Caldwell, S. D. (2007). Beyond change management: A multilevel investigation of contextual and personal influences on employees' commitment to change. Journal of Applied Psychology, 92(4), 942-951.

Hewett, R., Shantz, A., Mundy, J., \& Alfes, K. (2017). Attribution theories in human resource management research: A review and research agenda. The International Journal of Human Resource Management, 29(1), 87-126.

Home Office. (2012). Police service strength, England and Wales, 31 march 2012, from https://www.gov.uk/government/statistics/police-service-strength-england-and-wales-31$\underline{\operatorname{march}-2012}$

Hu, L.-t., \& Bentler, P. M. (1998). Fit indices in covariance structure modeling: Sensitivity to underparameterized model misspecification. Psychological Methods, 3(4), 424-453.

Jones, R. A., Jimmieson, N. L., \& Griffiths, A. (2005). The impact of organizational culture and reshaping capabilities on change implementation success: The mediating role of readiness for change. Journal of Management Studies, 42(2), 361-386. 
Judge, T. A., Thoresen, C. J., Pucik, V., \& Welbourne, T. M. (1999). Managerial coping with organizational change: A dispositional perspective. Journal of Applied Psychology, 84(1), $107-122$.

Kaplowitz, M. D., Hadlock, T. D., \& Levine, R. (2004). A comparison of web and mail survey response rates. Public Opinion Quarterly, 68(1), 94-101.

Kark Smollan, R. (2006). Minds, hearts and deeds: Cognitive, affective and behavioural responses to change. Journal of Change Management, 6(2), 143-158.

Katou, A. A., Budhwar, P. S., \& Patel, C. (2014). Content vs. Process in the HRM-performance relationship: An empirical examination. Human Resource Management, 53(4), 527-544.

Khatri, N., Gupta, V., \& Varma, A. (2017). The relationship between HR capabilities and quality of patient care: The mediating role of proactive work behaviors. Human Resource Management, 56(4), 673-691.

Kim, S., \& Ryu, S. (2011). Social capital of the HR department, HR's change agent role, and HR effectiveness: Evidence from South Korean firms. The International Journal of Human Resource Management, 22(8), 1638-1653.

Kim, T. G., Hornung, S., \& Rousseau, D. M. (2011). Change-supportive employee behavior: Antecedents and the moderating role of time. Journal of Management, 37(6), 1664-1693.

Koys, D. (1988). Human resource management and a culture of respect: Effects on employees' organizational commitment. Employee Responsibilities and Rights Journal, 1(1), 57-68.

Lazarus, R. S. (1991). Emotion and adaptation. New York: Oxford University Press. 
Lazarus, R. S., \& Folkman, S. (1984). Stress, appraisal and coping. New York Springer.

Lazarus, R. S., Kanner, A. D., \& Folkman, S. (1980). Emotions: A cognitive-phenomenological analysis. In R. Plutchik \& H. Kellerman (Eds.), Theories of emotion (pp. 189-217). New York: Academic Press.

Li, X., Frenkel, S. J., \& Sanders, K. (2011). Strategic HRM as process: How HR system and organizational climate strength influence Chinese employee attitudes. The International Journal of Human Resource Management, 22(9), 1825-1842.

Liu, Y., \& Perrewé, P. L. (2005). Another look at the role of emotion in the organizational change: A process model. Human Resource Management Review, 15(4), 263-280.

Long, C. S., Wan Ismail, W. K., \& Amin, S. M. (2013). The role of change agent as mediator in the relationship between HR competencies and organizational performance. The International Journal of Human Resource Management, 24(10), 2019-2033.

Mathieu, J. E., \& Taylor, S. R. (2006). Clarifying conditions and decision points for mediational type inferences in organizational behavior. Journal of Organizational Behavior, 27(8), 10311056.

McDermott, A., \& Conway, E. (2016). HRM and organisational change: Integrating multiple levels of analysis. In T. Redman, A. Wilkinson, \& T. Dundon (Eds.), Contemporary human resource management: Text and cases (5 ed.). London: Palgrave-Macmillan.

Podsakoff, P. M., MacKenzie, S. B., Jeong-Yeon, L., \& Podsakoff, N. P. (2003). Common method biases in behavioral research: A critical review of the literature and recommended remedies. Journal of Applied Psychology, 88(5), 879-903. 
Rafferty, A. E., \& Griffin, M. A. (2006). Perceptions of organizational change: A stress and coping perspective. Journal of Applied Psychology, 91(5), 1154-1162.

Rafferty, A. E., \& Restubog, S. L. D. (2017). Why do employees' perceptions of their organization's change history matter? The role of change appraisals. Human Resource Management, 56(3), 533-550.

Reddy, S. K. (1992). Effects of ignoring correlated measurement error in structural equation models. Educational and Psychological Measurement, 52(3), 549-570.

Rhoades, L., \& Eisenberger, R. (2002). Perceived organizational support: A review of the literature. Journal of Applied Psychology, 87(4), 698-714.

Richardson, H. A., Simmering, M. J., \& Sturman, M. C. (2009). A tale of three perspectives: Examining post hoc statistical techniques for detection and correction of common method variance. Organizational Research Methods, 12(4), 762-800.

Ritz, A., Shantz, A., Alfes, K., \& Arshoff, A. S. (2012). Who needs leaders the most? The interactive effect of leadership and core self-evaluations on commitment to change in the public sector. International Public Management Journal, 15(2), 160-185.

Rodrigues Ribeiro, T., Pinto Coelho, J., \& Gomes, J. F. S. (2011). HRM strength, situation strength and improvisation behavior. Management Research: Journal of the Iberoamerican Academy of Management, 9(2), 118-136.

Sanders, K., Dorenbosch, L., \& De Reuver, R. (2008). The impact of individual and shared employee perceptions of HRM on affective commitment: Considering climate strength. Personnel Review, 37(4), 412-425. 
Scherer, K. (1999). Appraisal theory. In T. Dalgleish \& M. Power (Eds.), Handbook of emotion and cognition (pp. 637-665). New York: Wiley.

Schumacher, D., Schreurs, B., Van Emmerik, H., \& De Witte, H. (2016). Explaining the relation between job insecurity and employee outcomes during organizational change: A multiple group comparison. Human Resource Management, 55(5), 809-827.

Schweiger, D. M., \& Denisi, A. S. (1991). Communication with employees following a merger: A longitudinal field experiment. Academy of Management Journal, 34(1), 110-135.

Self, D. R., Armenakis, A. A., \& Schraeder, M. (2007). Organizational change content, process, and context: A simultaneous analysis of employee reactions. Journal of Change Management, 7(2), 211-229.

Shin, J., Taylor, M. S., \& Seo, M.-G. (2012). Resources for change: The relationships of organizational inducements and psychological resilience to employees' attitudes and behaviors toward organizational change. Academy of Management Journal, 55(3), 727-748.

Spector, P. E., Rosen, C. C., Richardson, H. A., Williams, L. J., \& Johnson, R. E. (2017). A new perspective on method variance (online first). Journal of Management.

Storey, J. (1992). Developments in the management of human resources. An analytical review. Oxford: Blackwell.

Teece, D. J., Pisano, G., \& Shuen, A. (1997). Dynamic capabilities and strategic management. Strategic Management Journal, 18(7), 509-533. 
Troup, C., \& Dewe, P. (2002). Exploring the nature of control and its role in the appraisal of workplace stress. Work \& Stress, 16(4), 335-355.

Truss, C. (2013). The distinctiveness of HRM in the public sector. In R. Burke, A. Noblet, \& C. Cooper (Eds.), Human resource management in the public sector (pp. 17-36). London: Edward Elgar.

Tyson, S., \& Fell, A. (1992). Evaluating the personnel function (2 ed.). Leckhampton: Thornes.

Ulrich, D. (1997). Human resource champions. The next agenda for adding value and delivering results. Boston: Harvard Business School Press.

Ulrich, D. (1998). A new mandate for human resources. Harvard Business Review, 76(1), 124-134.

Walker, H. J., Armenakis, A. A., \& Bernerth, J. B. (2007). Factors influencing organizational change efforts: An integrative investigation of change content, context, process and individual differences. Journal of Organizational Change Management, 20(6), 761-773.

Wanberg, C. R., \& Banas, J. T. (2000). Predictors and outcomes of openness to changes in a reorganizing workplace. Journal of Applied Psychology, 85(1), 132-142.

Watson, D. (2000). Mood and temperament: Guilford Press.

Watson, D., Clark, L. A., \& Tellegan, A. (1988). Development and validation of brief measures of positive and negative affect: The PANAS scales. Journal of Personality and Social Psychology, 54(6), 1063.

Weick, K. E. (1995). Sensemaking in organizations. Thousand Oaks, CA: Sage. 
Whelan-Berry, K. S., Gordon, J. R., \& Hinings, C. R. (2003). Strengthening organizational change processes: Recommendations and implications from a multilevel analysis. The Journal of Applied Behavioral Science, 39(2), 186-207.

Williams, L. J., Hartman, N., \& Cavazotte, F. (2010). Method variance and marker variables: A review and comprehensive CFA marker technique. Organizational Research Methods, 13(3), $477-514$.

Winsor, T. P. (2012). Independent review of police officer and staff remuneration and conditions. London: The Stationery Office. 
FIGURE 1

Standardized Estimates of Final Model

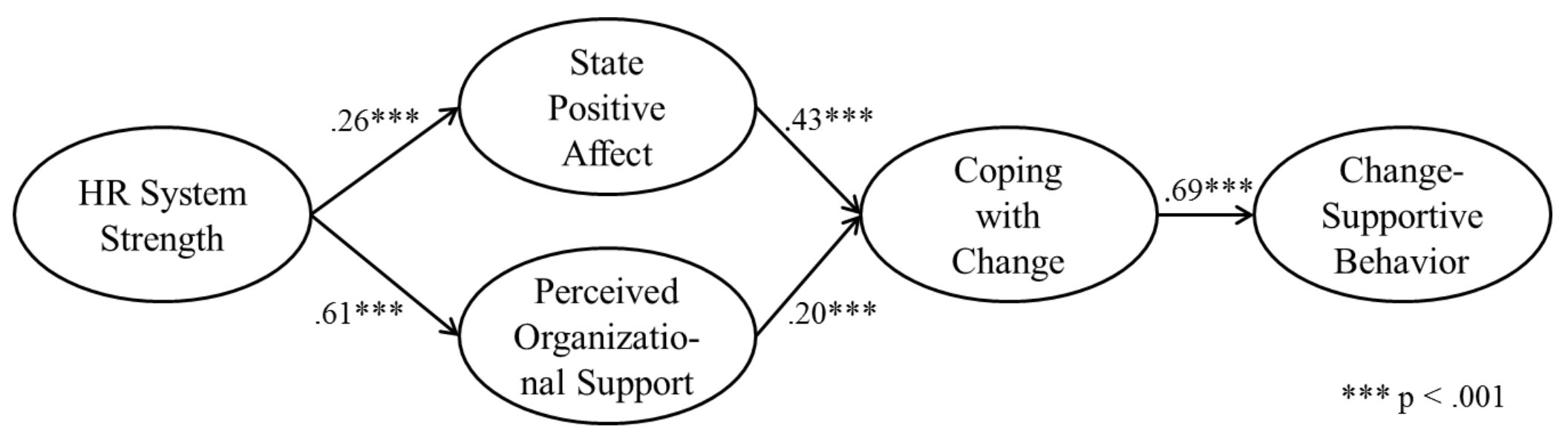


TABLE 1

Descriptive Statistics, Correlations and Scale Reliabilities for Study Variables

\begin{tabular}{|c|c|c|c|c|c|c|c|c|c|c|c|c|}
\hline & & Alpha & Mean & $\mathrm{SD}$ & 1 & 2 & 3 & 4 & 5 & 6 & 7 & 8 \\
\hline 1 & Gender $($ Female $=1)$ & $\mathrm{n} / \mathrm{a}$ & .41 & 4.92 & & & & & & & & \\
\hline 3 & Job Status $($ Officer $=1)$ & $\mathrm{n} / \mathrm{a}$ & .57 & .50 & $-.34 * *$ & $-.10 *$ & & & & & & \\
\hline 5 & State Positive Affect & .93 & 3.64 & .79 & -.07 & .00 & .01 & $.25^{* *}$ & $(.93)$ & & & \\
\hline 6 & Perceived Org Support & .93 & 2.39 & .91 & .04 & .00 & $-.11 *$ & $.58 * *$ & $.42 * *$ & $(.93)$ & & \\
\hline 7 & Coping with Change & .73 & 3.17 & .48 & -.02 & -.02 & $-.10 *$ & $.20 * *$ & $.41 * *$ & $.37 * *$ & $(.72)$ & \\
\hline
\end{tabular}

Notes: $\mathrm{n}=704 ; * * \mathrm{p}<.01,{ }^{*} \mathrm{p}<.05$. Cronbach Alpha values for each scale are reported on the diagonal in italics. 
TABLE 2

Fit Statistics from Measurement Model Comparison

\begin{tabular}{|c|c|c|c|c|c|c|c|}
\hline Models & $\chi^{2}(d f)$ & $I F I$ & $C F I$ & RMSEA & $S R M R$ & $\chi_{\text {diff }}^{2}$ & $d f_{\text {diff }}$ \\
\hline Full measurement model & $2046(618)$ & .91 & .91 & .06 & .06 & & \\
\hline Model A ${ }^{\mathrm{a}}$ & $5604(622)$ & .69 & .69 & .11 & .14 & 3540 & $4 * * *$ \\
\hline Model $\mathrm{B}^{\mathrm{b}}$ & $3557(622)$ & .82 & .82 & .09 & .09 & 1511 & $4 * * *$ \\
\hline Model C & $7154(625)$ & .59 & .59 & .13 & .13 & 5108 & $7 * * *$ \\
\hline Model D ${ }^{\mathrm{d}}$ & $2757(622)$ & .87 & .87 & .07 & .09 & 711 & $4 * * *$ \\
\hline Model E $\mathrm{E}^{\mathrm{e}}$ & $2853(622)$ & .86 & .86 & .07 & .10 & 807 & $4 * * *$ \\
\hline Model $F^{f}$ & $2349(622)$ & .89 & .89 & .07 & .07 & 303 & $4 * * *$ \\
\hline $\begin{array}{l}\text { Model G' } \\
\text { (Harman's Single Factor Test) }\end{array}$ & $9930(628)$ & .42 & .42 & .15 & .16 & 7884 & $10 * * *$ \\
\hline
\end{tabular}

Notes: $* * * \mathrm{p}<.001 ; \chi^{2}=$ chi-square discrepancy, $\mathrm{df}=$ degrees of freedom; IFI=Incremental Fit Index; CFI=Comparative Fit Index; RMSEA=Root Mean Square Error of Approximation; SRMR= Standardized Root Mean Square Residual; $\chi_{\text {diff }}^{2}=$ difference in chisquare, $d f_{\text {diff }}=$ difference in degrees of freedom. In all measurement models, error terms were free to covary between one pair of changesupportive behavior items to improve fit and help reduce bias in the estimated parameter values (Reddy, 1992). All models are compared to the full measurement model.

$\mathrm{a}=\mathrm{HR}$ system strength and state positive affect combined into a single factor

$\mathrm{b}=\mathrm{HR}$ system strength and perceived organizational support combined into a single factor

$\mathrm{c}=\mathrm{HR}$ system strength, state positive affect and perceived organizational support combined into a single factor

$\mathrm{d}=$ State positive affect and coping combined into a single factor

$\mathrm{e}=$ Perceived organizational support and coping combined into a single factor

$\mathrm{f}=$ Coping and change-supportive behavior combined into a single factor

$\mathrm{g}=\mathrm{All}$ factors combined into a single factor 
TABLE 3

Structural Equation Model Comparisons

\begin{tabular}{lcccccc}
\hline \multicolumn{1}{c}{ Models } & IFI & CFI & RMSEA & SRMR & Comparisons \\
\hline Saturated model & $2046(620)$ & .901 & .900 & .062 & .080 & \\
Direct effects model & $2682(628)^{* * *}$ & .857 & .856 & .074 & .196 & Compared to saturated model \\
Indirect effects model & $1474(624)^{* * *}$ & .916 & .916 & .057 & .080 & Compared to saturated model \\
\hline Notes: $\mathrm{n}=704 . * * * \mathrm{p}<.001$ & & & & & &
\end{tabular}

Notes: $\mathrm{n}=704 . * * * \mathrm{p}<.001$ 
APPENDIX A

Measures included in our study

HR System Strength

(Frenkel et al., 2012)

- HR practices here contribute to my work satisfaction

- Managers here don't implement HR policies properly (reverse scored)

- HR policies here are clearly communicated to employees

- Managers here adopt a similar approach to managing employees

- HR practices here make me feel much more confident in my ability to do my job well

- HR practices here help me to achieve my goals

- HR practices here help me a great deal to develop my knowledge and skills

- Managers here agree on how to implement HR policies

- HR practices here help me to achieve the company's goals

State Positive Affect

- Excited

- Strong

- Enthusiastic

- Attentive

- Active

- Proud

- Inspired

- Determined

- Interested

- Alert

Perceived Organizational Support

- My organisation cares about my opinions

- My organisation really cares about my well being

- My organisation strongly considers my goals and values

- My organisation shows a lot of concern for me Coping with Organizational Change

(Watson et al., 1988)

- When dramatic changes happen in my organization, I feel I handle them with ease

- Rapid change is something to adapt to, but not to embrace (reverse scored)

- When changes happen in my organization, I react by trying to manage the change rather than complain about it

(Eisenberger et al., 1986)

(Judge et al., 1999) 
- The changes occurring in my organization cause me stress (reverse scored)

- I see the rapid changes that are occurring in my organization as opening up new career opportunities for me

- When changes are announced, I try to react in a problemsolving, rather than an emotional, mode

- I often find myself leading change efforts in my organization

- I think I cope with change better than most of those with whom I work

Change-supportive behavior

(Giangreco \& Peccei, 2005)

- I co-operate actively to realize the change

- I encourage actions to support the realization of the change

- I promote the change with enthusiasm

- I try to convince others of the appropriateness of the change

- I sustain with vigour the change in public discussions

- I make considerable effort so that work colleagues understand the change 